\title{
STRESS CHARACTERISTICS AND STRESS REVERSAL MECHANISM OF WHITE BIRCH (Betula platyphylla) DISKS UNDER DIFFERENT DRYING CONDITIONS
}

\author{
Zongying Fu ${ }^{1}$, Jingyao Zhao ${ }^{1}$, Yangyi Lv ${ }^{1}$, Siqi Huan ${ }^{1}$, Yingchun Cai ${ }^{1, \star}$
}

\begin{abstract}
Drying stress is the main cause for the generation of drying cracks in wood disks during drying, which limits the processing and utilization of this valuable material. For this study, white birch disks with one trunk and a thickness of $30 \mathrm{~mm}$ were dried under three different drying conditions: 1) a very slow drying process preventing the generation of a radial moisture content (MC) gradient, 2) a drying process with slowly increasing temperature leading to a radial $\mathrm{MC}$ gradient, with a higher $\mathrm{MC}$ in the heartwood, and 3) the same heat drying process but the wood disks were partly covered with a thin plastic film prior to the drying process leading to a reversed radial $\mathrm{MC}$ gradient, i.e., a higher $\mathrm{MC}$ in the sapwood. For each drying condition, the tangential elastic strain in the wood disks was investigated for a mean $\mathrm{MC}$ of $26 \%, 18 \%$ and $10 \%$, respectively, as a function of the radial distance from the pith in order to predict the drying stress. Furthermore, the stress characteristics and stress reversal mechanisms in wood disks are discussed in this paper with the help of stress analysis sketches.
\end{abstract} disks.

Keywords: Drying strain, drying stress, moisture content gradient, stress analysis, white birch

\section{INTRODUCTION}

The utilization of wood, a renewable and recyclable material, offers environmental and ecological benefits. The search for more efficient processing and utilization methods of this valuable material has received more and more attention. Wood drying is considered one of the most important and complex processing operations. Achieving high drying quality, short drying time and low energy consumption is crucial to the wood industry. In times of wood shortage and greenhouse effect, a better utilization of inferior wood resources, e.g., small-diameter or crooked logs, is an effective way to save wood, and may help to achieve carbon sequestration and environmental protection goals. 
Cutting tree logs into wood disks is feasible for improving the utilization of small-diameter or crooked logs because the waste produced during the logging and sawing process is much lower for cross-sectional cuts than for lumber that is cut lengthwise. However, drying defects are generated more easily in wood disks, especially in larger diameter ones than in sawed lumber for several reasons (Zanucio et al. 2015). First, transverse anisotropy is prominent in cross-sections, such as different shrinkage coefficients for the tangential and radial direction. Second, due to the material inhomogeneity, wood disks contain different types of wood, i.e., juvenile wood and mature wood as well as heartwood and sapwood (Yamashita et al. 2009). Such variations make it difficult to prevent drying defects in wood disks during drying.

Drying defects (cracks, warps and deformations) are mainly generated by drying stress caused by shrinkage anisotropy and moisture content (MC) gradients (Hasalania and Itayaa 1996). Drying stress is a kind of mutual effect among the wood tissues generated during drying. It cannot be directly assessed because of its variation with changes in temperature and humidity. Usually, the strain is measured at a specific stage during drying to reflect the drying stress. The majority of studies on drying stress have been performed using traditionally sawed lumber. For instance, the stress and rheological behavior during conventional drying has been investigated by Zhan et al. (2009a, b, 2011). Pang and Svensson have developed mathematical models to predict the drying stress and deformation for overall changes in MC (Pang 2000, 2002, 2007, Svensson and Mårtensson 1999, 2002).

For the drying of wood disks, traditional drying theories for sawed lumber no longer apply. Despite some efforts in finding suitable principles applicable to the drying of wood disks, only a few achievements have been made. In the 1970s, Kubler reported on the drying of wood disks without defects at different temperatures and proposed an explanation for the cause of heat checks (Kubler 1974, 1975, 1977). Later, the application of radio-frequency/vacuum drying has been reported for the drying of wood disks (Lee et al. 1998, 2000, Li and Lee 2007). The variation of radial and tangential shrinkage, and the generation of drying defects in larch disks have been investigated by Kang et al. $(2004 \mathrm{a}, \mathrm{b})$ and Lee et al. (2004). Larsen and Ormarsson $(2013,2014)$ reported on drying experiments and numerical simulations based on finite element modeling of the moisture-induced stresses and strains, as well as the tangential tensile strength and fracture behavior under different climatic conditions.

For this study, the tangential elastic strains in wood disks were measured at each target MC for three different drying conditions. The drying stresses are evaluated by analyzing the measured drying strains which were generated by shrinkage anisotropy alone or by its interaction with an MC gradient. Furthermore, the stress characteristics and stress reversal mechanisms are discussed. The present study aimed to investigate the development of the drying stresses in wood disks for different drying conditions and to provide a theoretical framework for potential methods of restraining the occurrence of drying cracks in wood disks.

\section{Materials and methods}

22-year-old plantation white birch (Betula platyphylla Suk) trees with an average diameter of $25 \mathrm{~cm}$ were obtained from forests in the region of the Lesser Khingan Mountains, located in the Heilongjiang Province, China. The thinning intensity is $70 \%$, which has an effect on wood density and drying defects (Vallejos et al. 2015). The average initial MC of the wood was above $60 \%$, as shown in Figure 1 . The logs were sawed into wood disks with a thickness of $30 \mathrm{~mm}$ starting at a distance of $0,3 \mathrm{~m}$ from the roots. The disks were numbered, coated with plastic films, and stored in a freezer to keep them in green condition.

The experiments were conducted in a GDS-100 conditioning chamber. Based on previous studies (Zhao et al. 2013), two different drying schedules were applied, which are illustrated in Figure 1. Under Schedule 1, the temperature was kept constant at $40{ }^{\circ} \mathrm{C}$ and the relative humidity (RH) was successively decreased and balanced for $6 \mathrm{~h}$ at intervals of $12 \mathrm{~h}$ to ensure that the $\mathrm{MC}$ along the radial direction was more uniform. Under Schedule 2, the initial dry-bulb temperature was set to $40{ }^{\circ} \mathrm{C}$ and increased stepwise to the final temperature of $60^{\circ} \mathrm{C}$. The RH was decreased from $100 \%$ to $65 \%$ over a time period of $144 \mathrm{~h}$. Above and below the fiber saturation point (FSP), the dry-bulb temperature was increased by $2{ }^{\circ} \mathrm{C}$ at intervals of $24 \mathrm{~h}$ and $12 \mathrm{~h}$, respectively. 


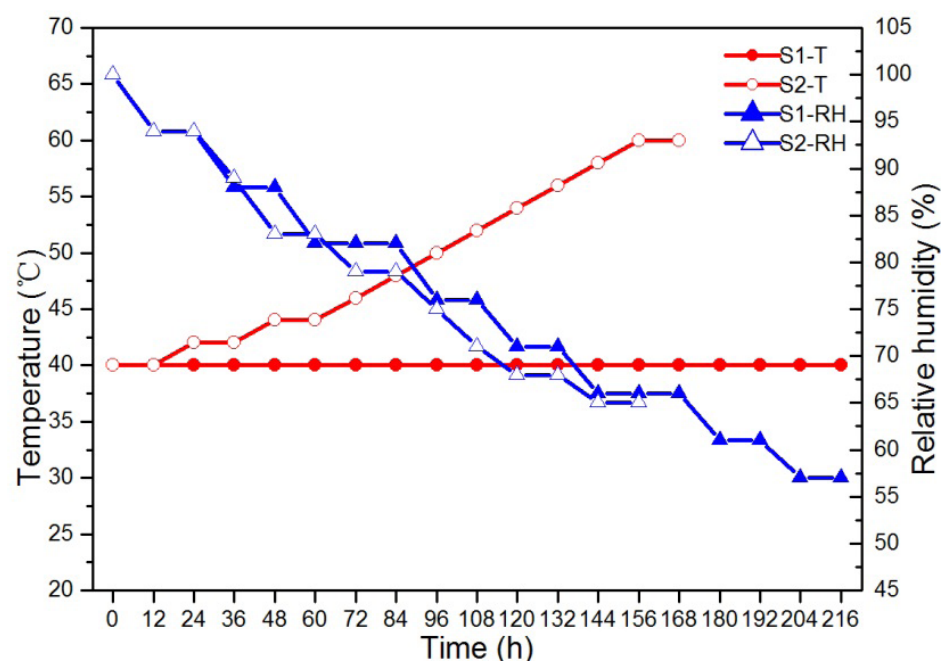

Figure 1. Illustration of the two different drying schedules, Schedule 1 and Schedule 2, showing the change in temperature and $\mathrm{RH}$ with time.

Thirty wood disks without visible defects were selected from one of the white birch trunks. The proportion of sapwood to heartwood was 1,25-1,5. The average initial MCs of sapwood and heartwood were $68 \%$ and $55 \%$, respectively. The disks were divided into three batches. One batch was dried under Schedule 1 with a constant temperature, resulting in a uniform MC along the radial direction. The second batch was dried under Schedule 2, resulting in a radial MC gradient with a higher MC in heartwood. The third batch was also dried under Schedule 2. However, the sapwood of the wood disks was covered with a thin plastic film with small circular holes prior to the drying process, resulting in a radial MC gradient with a higher MC in the sapwood. For each batch, one of the samples was used to determine the initial $\mathrm{MC}$, three samples were used to determine the target $\mathrm{MC}$ and the remaining six samples were used for studying the elastic strains at each target mean $\mathrm{MC}$ of $26 \%, 18 \%$ and $10 \%$, respectively.

The sawn surface of the samples was polished and lined with a grid, as shown in Figure 2. The specimens for the strain measurements $[30 \times 10 \times 30 \mathrm{~mm}, \mathrm{~T} \times \mathrm{R} \times \mathrm{L}]$ were cut along the grid lines during the drying process after reaching the target MC. The elastic strain was measured at a given MC using the image analysis method, which was employed here as an image-based, non-contact method for measuring the dot pitch. Consecutive images of the samples (including a scale-plate) were taken during the drying process at different target MCs using high-resolution digital photography equipment. The images were subsequently imported into the Image J software to measure and analyze the actual length of the grid on the samples. Since generally the elastic strain occurs instantly under drying stress, the elastic strain is measured at a specific stage to reflect the drying stress at this moment. Figure 3 shows the size of the strain test specimens at different states during drying compared to previously reported results (Fu et al. 2013, Rice and Youngs 1990). The tangential elastic strain was calculated using the following equation:

$$
\varepsilon_{t}=\left(L_{1}-L_{2}\right) / L_{0}
$$

where $L_{0}$ is the distance in mm between two measuring points on the strain specimens under green conditions, $L$ is the distance in $\mathrm{mm}$ between two measuring points on the strain specimens before cutting at each target MC of $26 \%, 18 \%$, and $10 \%$, respectively, and $L_{2}$ is the distance in mm between two measuring points on the strain specimens after cutting along the grid line. 
The stress was evaluated according to the following formula:

$$
\sigma_{t}=E \varepsilon_{t}
$$

Where $E$ is the elastic modulus and $\varepsilon_{t}$ is the tangential elastic strain.

Within a wood disk, drying strain has larger influence on the drying stress compared with elastic modulus $(E)$. So the effect of elastic strain on the drying stress can be ignored, namely, qualitatively evaluated drying stress by elastic strain.

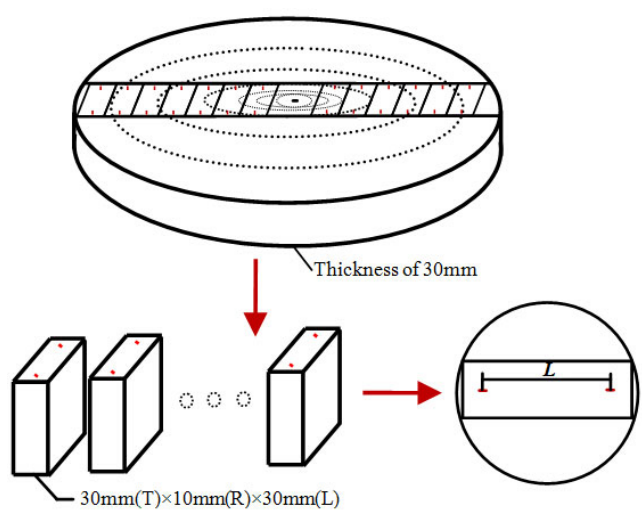

Figure 2. Illustration of the cutting of the wood disks and strain specimens.

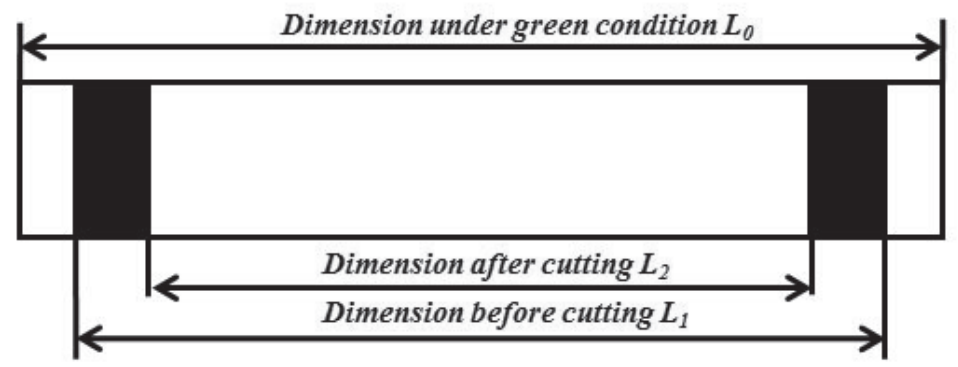

Figure 3. Comparison of the size of the strain specimens at different drying states. 


\section{RESULTS AND DISCUSSION}

\section{Distribution of moisture content}

The distribution of moisture content for heartwood and sapwood under different drying conditions is shown in Table 1. For drying condition 1, the level of MC almost keeps unchanged in heartwood and sapwood, and there is no MC gradient. For drying condition 2, at $26 \%$ and $18 \%$ average MC, the MC in heartwood is higher than in sapwood, which is contrary to drying condition 3 . When drying to $10 \%$ average $\mathrm{MC}$, the MC gradient is disappeared both in condition 2 and 3.

Table 1. Distribution of moisture content in wood disks.

\begin{tabular}{|c|c|c|c|c|c|c|}
\hline \multirow{2}{*}{$\begin{array}{c}\text { Moisture } \\
\text { content state }\end{array}$} & \multicolumn{2}{|c|}{ Drying condition 1 } & \multicolumn{2}{c|}{ Drying condition 2 } & \multicolumn{2}{c|}{ Drying condition 3 } \\
\cline { 2 - 7 } & Heartwood & Sapwood & Heartwood & Sapwood & Heartwood & Sapwood \\
\hline $\begin{array}{c}\text { Green wood } \\
66,5 \%\end{array}$ & $55,4 \%$ & $68,2 \%$ & $53,8 \%$ & $65,3 \%$ & $53,5 \%$ \\
\hline $\begin{array}{c}26 \% \text { Average } \\
\text { MC }\end{array}$ & $26,2 \%$ & $26,1 \%$ & $29,5 \%$ & $22,7 \%$ & $24,3 \%$ & $28,6 \%$ \\
\hline \begin{tabular}{c}
$18 \% \begin{array}{c}\text { Average } \\
\text { MC }\end{array}$ \\
\hline $\begin{array}{c}10 \% \text { Average } \\
\text { MC }\end{array}$
\end{tabular} & $18,1 \%$ & $18,2 \%$ & $21,4 \%$ & $16,4 \%$ & $16,2 \%$ & $20,8 \%$ \\
\hline
\end{tabular}

\section{Analysis of the stress caused by shrinkage anisotropy alone}

The tangential elastic strain caused by shrinkage anisotropy alone is depicted in Figure 4. The distribution of the elastic strain is roughly symmetrical to the pith where the elastic strain is at its minimum. This is consistent with previous studies reporting that shrinkage is minimal near the pith (Pang and Herritsch 2005, Ofori and Brentuo 2005). At a mean MC of $26 \%$, tensile strain was observed at each radial position. In contrast, for a mean $\mathrm{MC}$ of $18 \%$ and $10 \%$, compressive strain was observed at each radial position. However, the strain measured for an $\mathrm{MC}$ of $10 \%$ was lower than the corresponding strain detected for a mean $\mathrm{MC}$ of $18 \%$, which is attributed to the following two reasons: 1 ) the elastic modulus increased with the decreasing MC below the FSP (Tu et al. 2007); 2) the drying stress was released because of the occurrence of creep during early drying stages (Wu and Milota 1994).

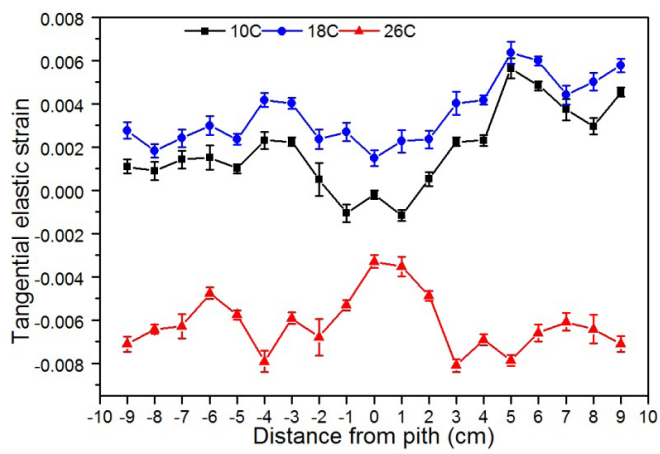

Figure 4. Variation of the tangential elastic strain measured from pith to bark for each target $\mathrm{MC}$ for drying under Schedule 1. 
Based on the size and orientation of the tangential elastic strain observed at different MCs, it can be speculated that stress reversal occurred when the mean MC of the wood disks decreased from $26 \%$ to 18\%. A stress reversal mechanism was proposed by Fu et al. (2013) and can be summarized as follows:

If the MC is below the FSP, the wood disks start to shrink due to the loss of bound water. Due to shrinkage anisotropy, shrinkage in the tangential direction is limited by the radial direction. Therefore, tensile stress is generated in the tangential direction and compressive stress in the radial direction. A tangential elastic strain instantly appears with the tangential stress, while viscoelastic creep strain emerges with time. Once the tangential stress exceeds the proportional limit, plastic deformation occurs. Tensile plastic deformation usually restrains the tangential shrinkage, while having no effect on the radial shrinkage. If the rates of tangential shrinkage and radial shrinkage are the same, there are no internal stresses in the wood disks. However, once the radial shrinkage rate exceeds the tangential shrinkage rate, stress reversal will begin.

\section{Analysis of the stress with interaction between shrinkage anisotropy and the radial MC gradient and a higher MC in the heartwood}

When the wood disks were dried under Schedule 2, the drying stress was induced by the interaction of shrinkage anisotropy and MC gradient. The radial variation of the tangential elastic strain measured for each target $\mathrm{MC}$ is depicted in Figure 5. At a mean MC of $26 \%$, for the majority of the radial measurement positions, a tangential tensile strain was observed. But a tangential compressive strain was found near the bark because stress reversal had already been completed at this position. This means that an additional tangential tensile stress was generated as soon as the MC near the bark had dropped below the FSP, resulting in a greater tangential tensile creep. Therefore, the stress reversal already occurred at an $\mathrm{MC}$ higher than $26 \%$. At a mean MC of $18 \%$, for each radial measurement position, a tangential compressive strain was observed. At the right side of the pith, the strain was found to increase from pith to bark. However, on the opposite side, some slight fluctuations were detected. Finally, at a mean MC of $10 \%$, a tangential compressive strain was still observed at each radial measurement position. But the values were considerably lower compared to the corresponding strain values at a mean MC of $18 \%$.

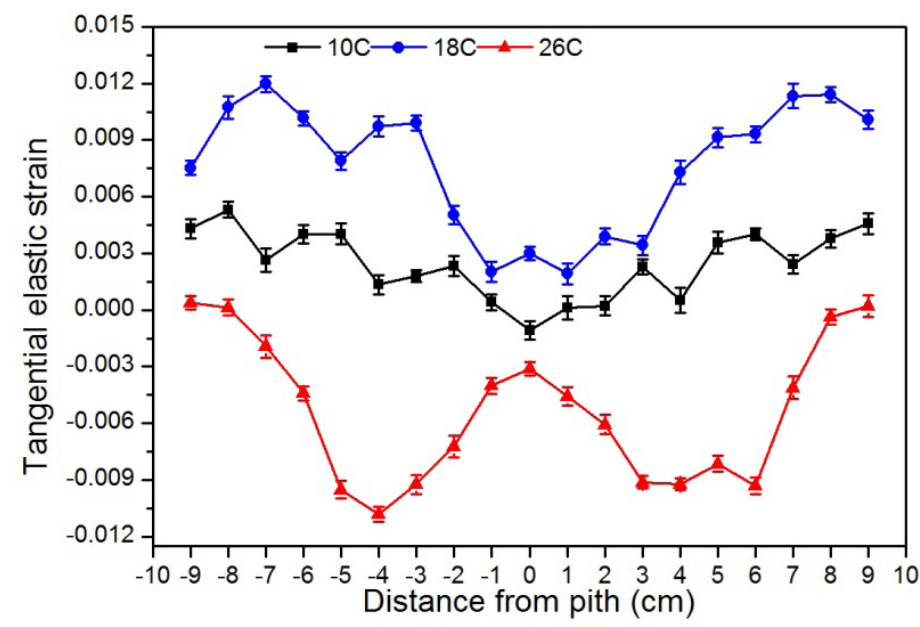

Figure 5. Radial distribution of the tangential elastic strain for each target MC for drying under Schedule 2. 
When the wood disks were dried under Schedule 2 without pretreatment, an MC gradient occurred, with the MC in heartwood being higher than in sapwood (Zhao 2013). The MC in sapwood decreased below the FSP first, leading to shrinkage. But the shrinkage in this region was restricted by both the heartwood and the mixed-wood (here: the transition region separating heartwood from sapwood), resulting in tangential tensile stress in the sapwood which was balanced by the compressive stress in the heartwood and the mixed-wood. In addition, due to shrinkage anisotropy, the shrinkage in the tangential direction was restricted by the shrinkage in the radial direction. Thus, an additional tangential tensile stress was generated in the sapwood, which was balanced by the radial compressive stress. Due to the combination of the tangential tensile stresses, a large creep was produced in the sapwood, limiting the shrinkage of the heartwood and the mixed-wood. As a result, the stress reversal was initiated. From this moment, the sapwood was subject to tangential compressive stress.

For the following theoretical considerations, a microelement was randomly selected from the sapwood. The analysis and composition of forces in the microelement prior to the stress reversal is shown in Figure 6a. In this Figure, $f_{t t}$ is the resulting sum of the tangential tensile stresses caused by shrinkage anisotropy and the MC gradient, while $f_{r c}$ and $f_{r c}^{\prime}$ denote the radial compressive stresses. The analysis and composition of forces after the stress reversal is shown in Figure 6b. Here, $f_{t c}$ denotes the tangential compressive stress, whereas $f_{r c}$ and $f_{r t}{ }_{r t}$ are the radial compressive stress and the radial tensile stress, respectively.

After drying to a mean $\mathrm{MC}$ of $10 \%$, the radial MC gradient had completely disappeared. Each layer was now only subject to the stress caused by shrinkage anisotropy alone. More precisely, each layer was subject to the tangential compressive stress $f_{t c}$ balanced by the radial tensile stresses $f_{r t}$ and $f_{r t}^{\prime}$. The corresponding forces are shown in Figure 6c.

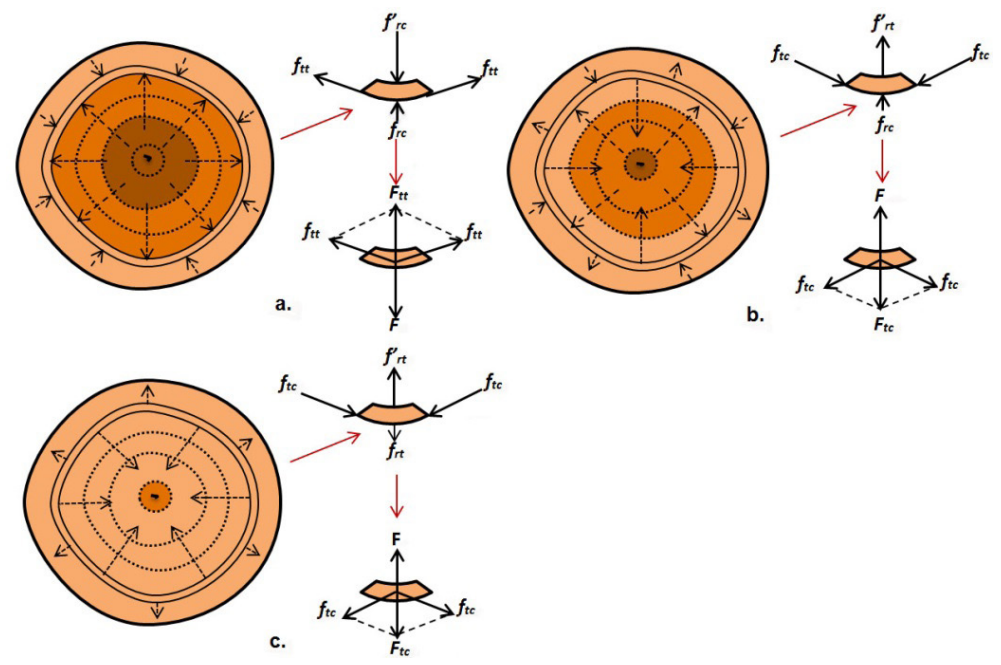

Figure 6. Sketches for the stress analysis with interaction between shrinkage anisotropy and the $\mathrm{MC}$ gradient ( $\mathrm{MC}$ in heartwood higher than in sapwood). The $\mathrm{MC}$ is represented by the difference in color: the darker the color, the higher the MC. a) MC of $26 \%$, b) $\mathrm{MC}$ of $18 \%$, c) MC of $10 \%$.

\section{Analysis of the stress with interaction between shrinkage anisotropy and the radial MC gradient and a higher MC in the sapwood}

Kubler reported that taping plastic film over wood disks may prevent a loss of moisture during drying (Kubler 1974). This method has been adopted for this study. Before drying, the sapwood of the third batch of wood disks was coated with a thin plastic film and then dried under Schedule 2. The radial distribution of the tangential elastic strain measured for each target $\mathrm{MC}$ is shown in figure 7. 
At a mean $\mathrm{MC}$ of $26 \%$, a tangential compressive strain was observed at each radial position, with the maximum strain value obtained at a distance of $70-80 \mathrm{~mm}$ from the pith, which is the area in proximity to the edge of the plastic film. At a mean $\mathrm{MC}$ of $18 \%$, the value of the tangential elastic strain was observed to fluctuate around zero because at this stage most of the MC gradient stresses have been neutralized by the shrinkage anisotropy stresses. After drying to a mean $\mathrm{MC}$ of $10 \%$, a lower tangential tensile strain was observed for each radial position except for the pith, and the strain was found to decrease from pith to bark.

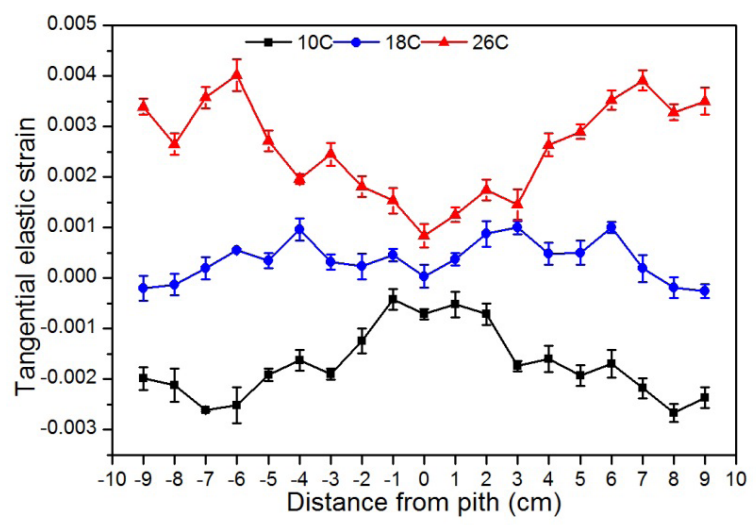

Figure 7. Radial distribution of the tangential elastic strain for each target MC for drying under Schedule 2 and the sapwood covered with a thin plastic film.

When the sapwood of the wood disks was covered with the thin film prior to the drying process, a radial MC gradient was observed, with a higher MC in the sapwood. The MC in the heartwood dropped below the FSP first, and the shrinkage started to occur in this area. However, the shrinkage in the heartwood was limited by the shrinkage in the surrounding areas.

For the following considerations, a microelement was randomly selected as the subject of interest from the mixed-wood. The forces caused by shrinkage anisotropy on this microelement are shown in Figure $8 \mathrm{a} . F_{1}$ is generated by the inhibitory effect of the radial shrinkage on the tangential shrinkage due to the different shrinkage coefficients for tangential and radial direction. $F_{2}$ is the radial compressive stress generated by the adjacent outer layer. The resulting tangential stress $T$ is balanced by the resulting radial force $F$. The forces caused by the $\mathrm{MC}$ gradient are shown in Figure 8b. $F_{3}$ and $F_{4}$ denote the radial tensile stress generated by the adjacent inner layer and outer layer, respectively. $T$ ' is the resulting force of the tangential compressive stresses $T_{3}$ and $T_{4}$ balanced by the resulting radial force $F^{\prime}$. According to the stress analysis above, the vectors of the stresses caused by shrinkage anisotropy and the MC gradient are pointing in opposite directions. Thus the resulting stress depends on the difference in magnitude and direction between the shrinkage anisotropy stress and the stress induced by the MC gradient. If the shrinkage anisotropy stress is greater than the MC gradient stress, the resulting stress is a tangential tensile stress. In the opposite case, the resulting stress is a tangential compressive stress. If the two balance each other, there is no resulting stress in the wood disks, which would be the desired state. 


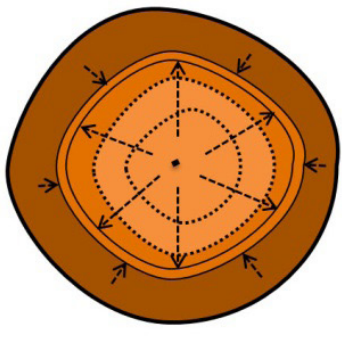

a
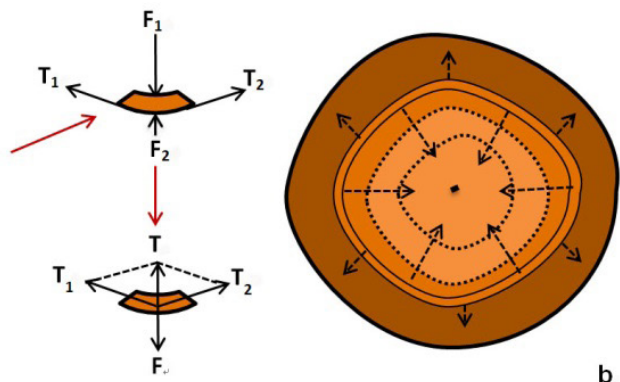

b

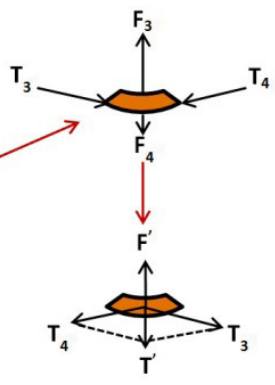

Figure 8. Sketches for the stress analysis with interaction between shrinkage anisotropy and the MC gradient ( $\mathrm{MC}$ in heartwood lower than in sapwood). The MC is represented by the difference in color: the darker the color, the higher the MC. a) stress induced by shrinkage anisotropy, b) stress induced by the MC gradient.

As a conclusion of this analysis, in general, the drying stress can be controlled by changing the MC gradient. However, the local MC in the wood disks is constantly changing during the drying process and it is difficult to continuously balance the shrinkage anisotropy stress and the MC gradient stress. In theory, the compressive strength of wood is much greater than the tensile strength perpendicular to the wood grain (Liu and Zhao 2004). Therefore, it is difficult to produce drying defects under tangential compressive stress. Thus, when the MC in sapwood is higher than in heartwood, it is better to ensure that the $\mathrm{MC}$ gradient stress is larger than the shrinkage anisotropy stress.

\section{CONCLUSIONS}

This study aimed to analyze the drying stresses in white birch disks under three different drying conditions. The results can be summarized as follows:

With the effect of shrinkage anisotropy alone, the tangential tensile stress is balanced by the radial compressive stress, and stress reversal (from tensile to compressive stress) occurred in the tangential direction as the MC dropped from $26 \%$ to $18 \%$. With interaction between shrinkage anisotropy and the MC gradient, when the MC in heartwood is higher than in sapwood, the vectors of the shrinkage anisotropy stress and the MC gradient stress are pointing in the same direction, and the additional tangential tensile stress accelerated the stress reversal.

When the MC in heartwood is lower than in sapwood, the vectors of the shrinkage anisotropy stress and the MC gradient are pointing in opposite directions. The practical drying stress depends on the magnitudes of the shrinkage anisotropy stress and the MC gradient stress. If the shrinkage anisotropy stress is larger than the MC gradient stress, the practical drying stress is tangential tensile stress. In the opposite case, the practical drying stress is tangential compressive stress.

Future studies will aim to further explore possibilities for lowering the drying stress by changing the MC gradient. 


\section{ACKNOWLEDGMENTS}

The National Natural Science Foundation of China (Grant No.: 31270595) and the Fundamental Research Funds for the Central Universities of China (Grant No.: 2572015AB08), financially supported this research.

\section{REFERENCES}

Fu, Z.Y.; Cai, Y.C; Zhao, J.Y.; Huan, S.Q. 2013. The effect of shrinkage anisotropy on tangential rheological properties of Asian white birch disks. BioResources 8(4):5235-5243.

Hasalania, M.; Itayaa, Y. 1996. Drying-induced strain and stress: a review. Drying Technology 14(5):1011-1040.

Kang, W.; Lee, N.H. 2004. Relationship between radial variations in shrinkage and drying defects of tree disk. Journal of Wood Science 50(3):209-216.

Kang, W.; Lee, N.H.; Choi, J.H. 2004b. A radial distribution of moistures and tangential strains within a larch log cross section during radio-frequency/vacuum drying. Holz als Roh- und Werkstoff 62(1):59-63. 35 .

Kubler, H. 1974. Drying tree disks simply and without defects. Forest Products Journal 24(7):33-

Kubler, H. 1975. Study on drying of tree cross sections. Wood Science 7(3):173-181.

Kubler, H. 1977. Formation of checks in tree stems during heating. Forest Products Journal 27:41-46.

Larsen, F.; Ormarsson, S. 2013. Numerical and experimental study of moisture-induced stress and strain field developments in timber logs. Wood Science and Technology 47:837-852.

Larsen, F.; Ormarsson, S. 2014. Experimental and finite element study of the effect of temperature and moisture on the tangential tensile strength and fracture behavior in timber logs. Holzforschung 68(1):133-140.

Lee, N.H.; Hayashi, K. 2000. Effect of end-covering and low pressure steam explosion treatment on drying rate and checking during radio-frequency/vacuum drying of Japanese cedar log cross sections. Forest Products Journal 50(2):73-79.

Lee, N.H.; Hayashi, K.; Jung, H.S. 1998. Effect of radio-frequency/vacuum drying and mechanical press-drying on shrinkage and checking of walnut log cross sections. Forest Products Journal 48(5):73-79.

Lee, N.H.; Li, C.; Choi, J.H.; Hwang, U.D. 2004. Comparison of moisture distribution along radial direction in a log cross section of heartwood and mixed sapwood and heartwood during radiofrequency/vacuum drying. Journal of Wood Science 50(4):484-489. 
Li, C.Y.; Lee, N.H. 2007. Effect of external compressive load on tangential strain behavior in Japanese larch log cross sections during radio-frequency/vacuum drying. Journal of Wood Science 53(4):291-295.

Liu, Y.X.; Zhao, G.J. 2004. Wood science. China Forestry Publishing, Beijing.

Ofori, J.; Brentuo, B. 2005. Green moisture content, basic density, shrinkage and drying characteristics of the wood of Cedrela odorata grown in Ghana. Journal of Tropical Forest Science 17(2):211-223.

Pang, S. 2000. Modeling of stress development during drying and relief during steaming in Pinus radiata lumber. Drying Technology 18(8):1677-1696.

Pang, S. 2002. Predicting anisotropic shrinkage of softwood I: theories. Wood Science and Technology 36(1):75-91.

Pang, S. 2007. Mathematical modeling of kiln drying of softwood timber: model development, validation, and practical application. Drying Technology 25(3):421-431.

Pang, S.; Herritsch, A. 2005. Physical properties of earlywood and latewood of Pinus radiate D. Don: anisotropic shrinkage, equilibrium moisture content and fibre saturation point. Holzforschung 59(6):654-661.

Rice, R.W.; Youngs, R.L. 1990. The mechanism and development of creep during drying of red oak. Holz als Roh- und Werkstoff 48(1):73-79.

Svensson, S.; Martensson, A. 1999. Simulation of drying stresses in wood Part I: comparison between one and two dimensional models. Holz als Roh- und Werkstoff 57(2):129-136.

Svensson, S.; Martensson, A. 2002. Simulation of drying stresses in wood Part II: convective air drying of sawn timber. Holz als Roh- und Werkstoff 60(1):72-80.

Tu, D.Y.; Gu, L.B.; Liu, B.; Zhou, X. 2007. Modeling and on-line measurement of drying stress of Pinus massoniana board. Drying Technology 25(3):441-448.

Vallejos, J.; Moya, R.; Serrano, R. 2015. Effects of thinning on diameter, heartwood, density and drying defects of Gmelina arborea. Maderas-Cienc Tecnol 17(2):365-372.

Zanucio A.J.; Carvalho, A.G.; Da Silva, L.F.; Lima, J.T.; Trughilo, P.F.; Da Silva, J.R.M. 2015. Predicting moisture content from basic density and diameter during air drying of Eucalyptus and Corymbia logs. Maderas-Cienc Tecnol 17(2):335-344.

Wu, Q.; Milota, M.R. 1994. Effect of creep and mechano-sorptive effect on stress development during drying. Drying Technology 12(8):2057-2085.

Yamashita, K.; Hirakawa, Y.; Nakatani, H.; Ikeda M. 2009. Tangential and radial shrinkage variation within trees in sugi cultivars. Journal of Wood Science 55(3):161-168.

Zhan, J.F.; Avramidis, S. 2011a. Mechanosorptive creep of hemlock under conventional drying I: the determination of free shrinkage strain. Drying Technology 29(7):789-796.

Zhan, J.F.; Avramidis, S. 2011b. Mechanosorptive creep of hemlock under conventional drying II: description of actual creep behavior in drying lumber. Drying Technology 29(10):1140-1149. 
Zhan, J.F.; Gu, J.Y.; Shi, S.Q. 2009. Rheological behavior of larch timber during conventional drying. Drying Technology 27 (10):1041-1050.

Zhao, J.Y.; Cai, Y.C.; Fu, Z.Y. 2013. Effect of white birch disk characteristics on drying check behaviors. Scientia Silvae Sinicae 49(7):129-135. 